\title{
Simulation Modeling Requirements for Loss-of-Control Accident Prevention of Turboprop Transport Aircraft
}

\author{
Dennis A. Crider ${ }^{1}$ \\ National Transportation Safety Board, Washington, DC, 20590 \\ and \\ John V. Foster ${ }^{2}$ \\ NASA Langley Research Center, Hampton, VA, 23681
}

\begin{abstract}
In-flight loss of control remains the leading contributor to aviation accident fatalities, with stall upsets being the leading causal factor. The February 12, 2009. Colgan Air, Inc., Continental Express flight 3407 accident outside Buffalo, New York, brought this issue to the forefront of public consciousness and resulted in recommendations from the National Transportation Safety Board to conduct "training that incorporates stalls that are fully developed" and develop simulator standards to support such training. In 2010, Congress responded to this accident with Public Law 11-216 (Section 208), which mandates full stall training for Part 121 flight operations. Efforts are currently in progress to develop recommendations on implementation of stall training for airline pilots. The International Committee on Aviation Training in Extended Envelopes (ICATEE) is currently defining simulator fidelity standards that will be necessary for effective stall training. These recommendations will apply to all civil transport aircraft including straight-wing turboprop aircraft. Government-funded research over the previous decade provides a strong foundation for stall/post-stall simulation for swept-wing, conventional tail jets to respond to this mandate, but turboprops present additional and unique modeling challenges. First among these challenges is the effect of power, which can provide enhanced flow attachment behind the propellers. Furthermore, turboprops tend to operate for longer periods in an environment more susceptible to ice. As a result, there have been a significant number of turboprop accidents as a result of the early (lower angle of attack) stalls in icing. The vulnerability of turboprop configurations to icing has led to studies on ice accumulation and the resulting effects on flight behavior. Piloted simulations of these effects have highlighted the important training needs for recognition and mitigation of icing effects, including the reduction of stall margins. This paper addresses simulation modeling requirements that are unique to turboprop transport aircraft and highlights the growing need for aerodynamic models suitable for stall training for these configurations. A review of prominent accidents that involved aerodynamic stall is used to illustrate various modeling features unique to turboprop configurations and the impact of stall behavior on susceptibility to loss of control that has led to new training requirements. This is followed by an overview of stability and control behavior of straight-wing turboprops, the related aerodynamic characteristics, and a summary of recent experimental studies on icing effects. In addition, differences in flight dynamics behavior between swept-wing jets and straight-wing turboprop configurations are discussed to compare and contrast modeling requirements. Specific recommendations for aerodynamic models along with further research needs and data measurements are also provided.
\end{abstract}

\footnotetext{
${ }^{1}$ Chief Technical Advisor, Vehicle Simulation, Researrch and Engineering, RE-1, AIAA Senior Member.

${ }^{2}$ Aerospace Technologist, Flight Dynamics Branch, MS 308, AIAA Associate Fellow.
} 


\section{Nomenclature}

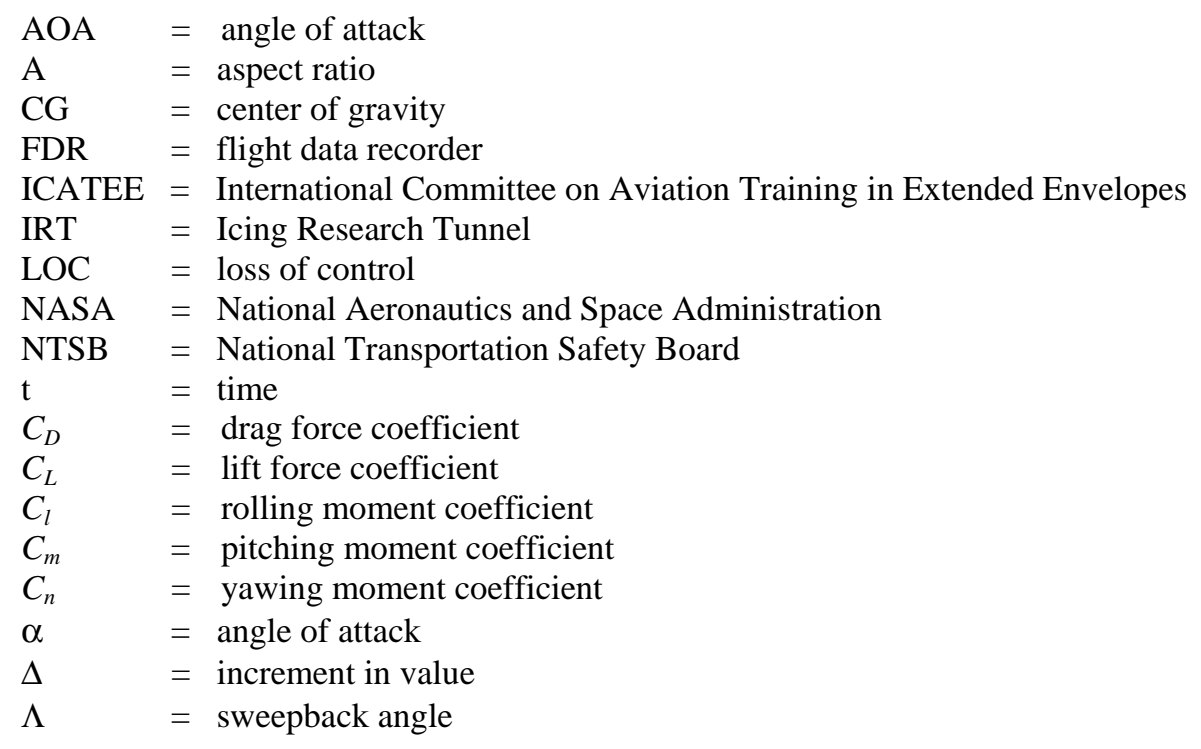

\section{Introduction}

Tn flight loss of control accidents can be generally divided into four groups of causes: upsets caused by 1 mechanical/system failures (includes pitot-static failure), spatial disorientation upsets, stall upsets (with and without ice), and icing upsets other than stall (controls/engine). A breakdown of worldwide turboprop loss of control accidents by cause from 2002 to 2011 is given in figure 1. Though improvements may be needed in some aspects of system modeling, aerodynamic models are generally adequate for mechanical and spatial disorientation upsets (at least initially, as such upsets can lead to a high angle of attack and sideslip). However, modeling enhancements are required for the stall and post-stall regions and for simulations with ice contaminations. Such simulation modeling enhancements are needed both for stall training and for development and validation of upset-countering technologies.

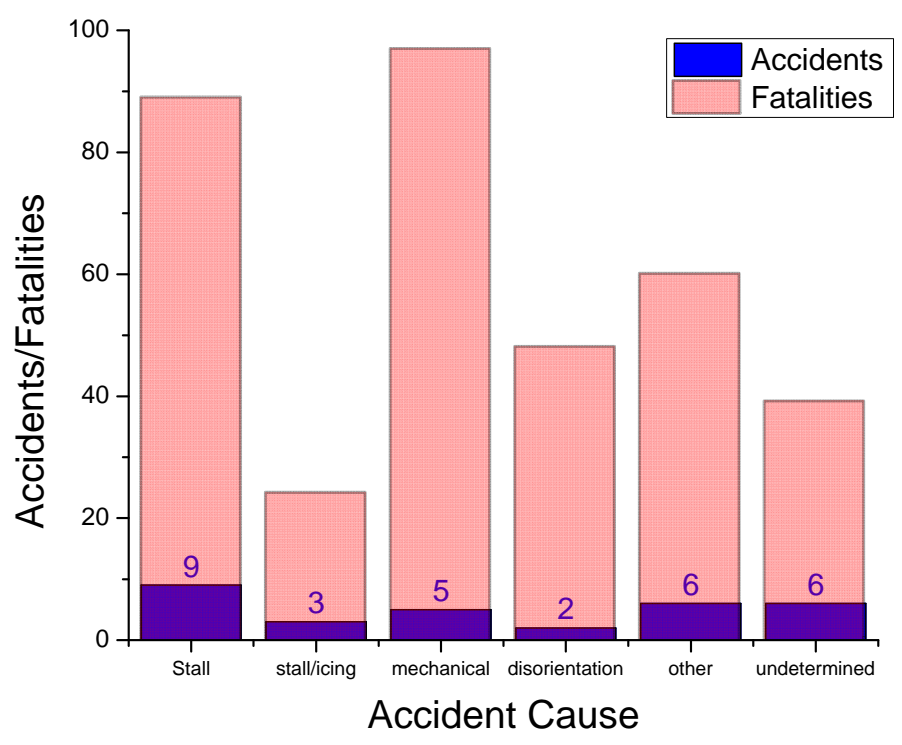

Figure 1. Turboprop loss of control accidents by cause, 2002 to 2011 (ref. 1). 
In response to the Colgan Air flight 3407 accident (to be discussed in a later section), Public Law 11-216, Section 208 now requires training for recovery from full stalls based on implementation of NTSB flight crewmember training recommendations (bold added for emphasis).

The Administrator of the Federal Aviation Administration shall conduct a rulemaking proceeding to require part 121 air carriers to provide flight crewmembers with ground training and flight training or flight simulator training to recognize and avoid a stall upset of an aircraft or, if not avoided, to recover from the stall;

The International Committee on Aviation Training in Extended Envelopes (ICATEE) is currently developing upset/stall training requirements and the recommendations have divided training tasks into three general topics;

- Avoidance,

- Recognition, and

- Recovery.

For training purposes, the emphasis is placed on avoidance and recognition with the expectation that early pilot intervention will minimize the potential for LOC events. Cues for stall upset recognition can occur before, during, and after the actual stall. ICATEE recommendations for stall modeling features include reduction in roll/yaw stability, uncommanded roll, and reduction of roll control effectiveness to recover from uncommanded roll.

While turboprop configurations exhibit unique flight behavior, they also pose a unique vulnerability to airframe icing due to extended flight at low altitudes. Furthermore, icing can reduce the stall angle of attack below the trigger value for stall warning systems. Training for recognition of these stall cues just before, during and after the actual stall dictates that the stall and post-stall region be correctly modeled. Training for stall recovery naturally requires accurate modeling, as stalls recognized during or just before the stall break can transition into the full stall region. In extreme cases, the first indication of stall can be a departure from controlled flight, such as an abrupt roll to extreme attitudes. Accordingly, training for stall upset recognition and recovery is particularly important.

\section{Recent Accidents}

Accident/incident analyses can provide a useful guide for identifying training needs. Accidents can be divided into uncontaminated and contaminated wing (icing). Recognition of natural stall cues (lateral stability reduction, uncommanded roll, and reduced roll control effectiveness) is particularly important for stall upsets in icing. The following section includes discussion of selected turboprop LOC events that serve to highlight important aircraft behaviors and operational circumstances that should be considered when developing aerodynamic models for training simulators. Specific NTSB recommendations relevant to aerodynamic modeling for these events are provided to highlight the importance of simulator fidelity for accident prevention.

\section{A. Turboprop LOC Accident With Uncontaminated Wing}

The February 12, 2009, crash of Colgan Air, Inc., Continental Express flight 3407 (operating as Continental Connection) in Clarence Center, New York, is an example of a turboprop LOC stall accident with an uncontaminated wing. ${ }^{2}$ Though the aircraft had flown through icing conditions during the flight, there was no significant degradation in aerodynamics at the time of the upset. The aircraft, a Bombardier DHC-8-400 (fig. 1), lost control on approach to Buffalo, New York, after a regularly scheduled flight from Newark, New Jersey. 


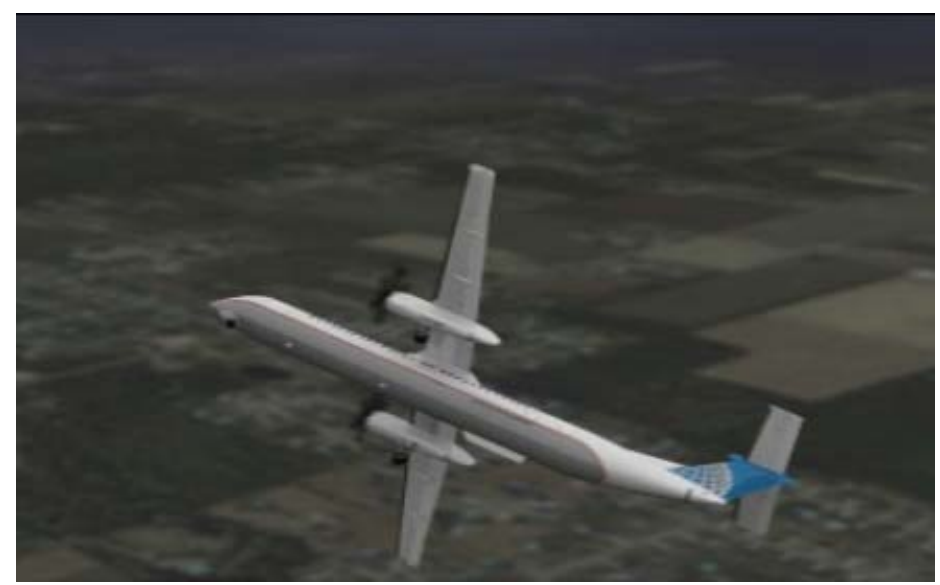

Figure 2. Bombardier DHC-8-400 aircraft.

Recorded flight data, shown in figs. 3 and 4, indicated the aircraft slowed to stick shaker airspeed after a power reduction. The pilot then applied aft column resulting in a full stall. At stall, an uncommanded roll occurred, leading to a series of roll oscillations which were ineffectively opposed by wheel inputs. Furthermore, the column remained aft as the crew ignored the stick shaker and pulled back against the stick pusher keeping the aircraft in a full stall to ground impact. Such dynamics and control wheel ineffectiveness are typical of stall departures and can thus be an important cue to the flight crew that the aircraft is stalled and that the pilot needs to pitch down to recover. Thus, correctly modeling these characteristics is an important precursor to simulator stall upset recognition and recovery training.

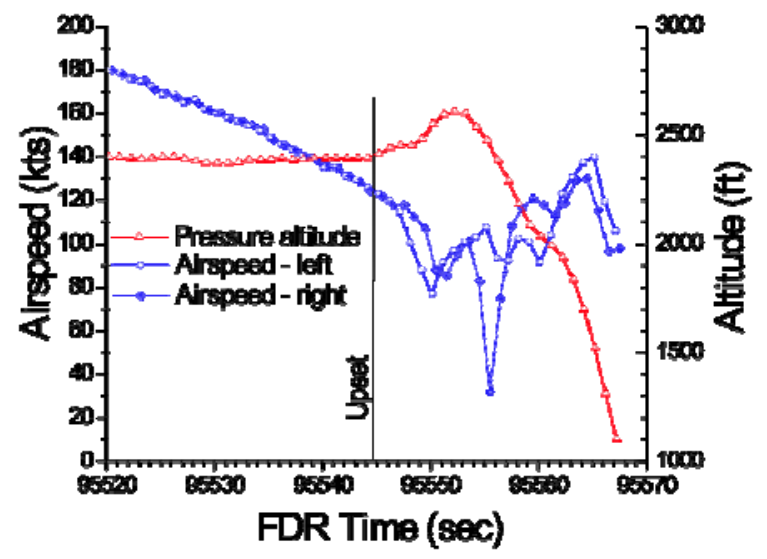

Figure 3. Time histories of airspeed and altitude (Colgan Air flight 3407).
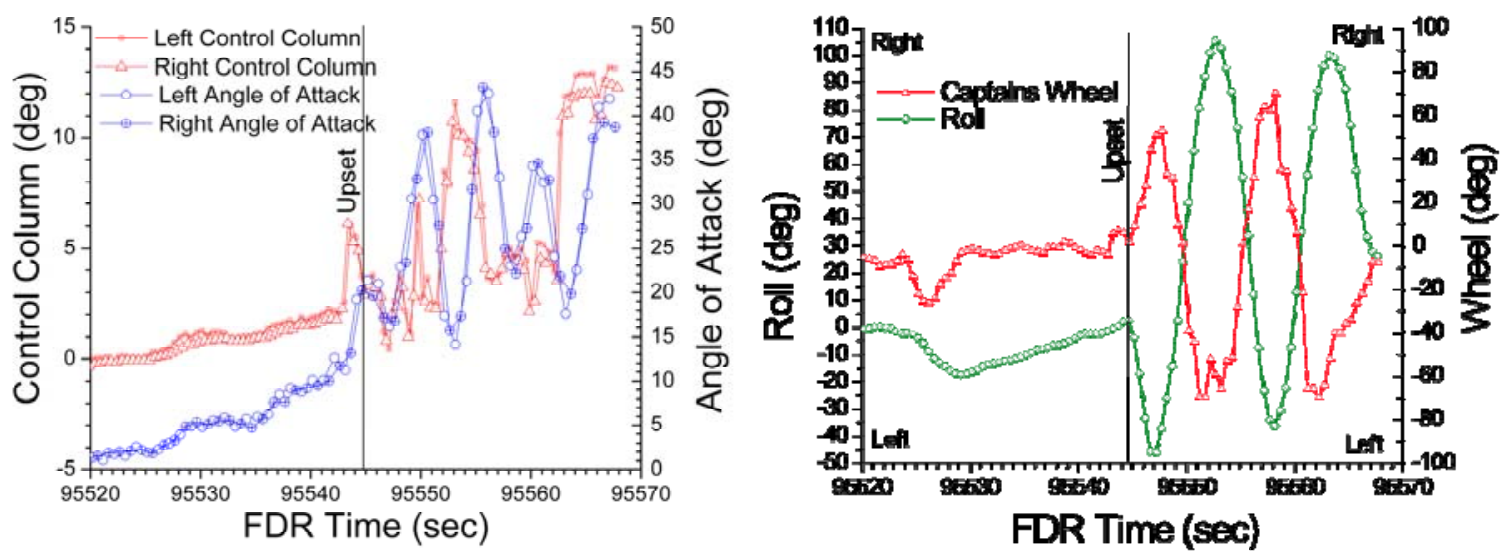
Figure 4. Time histories of control inputs (Colgan Air flight 3407).

The National Transportation Safety Board (NTSB) determined that the probable cause of the accident was:

... the captain's inappropriate response to the activation of the stick shaker, which led to an aerodynamic stall from which the airplane did not recover. Contributing to the accident were (1) the flight crew's failure to monitor airspeed in relation to the rising position of the low-speed cue, (2) the flight crew's failure to adhere to sterile cockpit procedures, (3) the captain's failure to effectively manage the flight, and (4) Colgan Air's inadequate procedures for airspeed selection and management during approaches in icing conditions.

Among the recommendations that the NTSB issued to the Federal Aviation Administration resulting from the Colgan Air accident investigation were three recommendations that addressed stall training, which were referred to by the U.S. Congress in Public Law 11-216.

\section{Recommendation A-10-22}

Require 14 Code of Federal Regulations Part 121, 135, and 91K operators and 14 Code of Federal Regulations Part 142 training centers to develop and conduct training that incorporates stalls that are fully developed; are unexpected; involve autopilot disengagement; and include airplanespecific features, such as a reference speeds switch.

\section{Recommendation A-10-23 (Supersedes Safety Recommendation A-07-4)}

Require all 14 Code of Federal Regulations Part 121, 135, and 91K operators of stick pusherequipped aircraft to provide their pilots with pusher familiarization simulator training.

\section{Recommendation A-10-24}

Define and codify minimum simulator model fidelity requirements to support an expanded set of stall recovery training requirements, including recovery from stalls that are fully developed. These simulator fidelity requirements should address areas such as required angle-of-attack and sideslip angle ranges, motion cueing, proof-of-match with post-stall flight test data, and warnings to indicate when the simulator flight envelope has been exceeded.

\section{B. Turboprop LOC Incidents/Accidents With Icing}

Some of the aerodynamic characteristics of icing stall upsets as well as the training needed to mitigate them are illustrated with three Saab 340 flaps up icing stall incidents and an ATR 42 icing stall upsets accident.

\section{Saab 340 Upsets}

The first example of a flap up Saab 340 stall upset in icing is American Eagle flight 3008. The aircraft was on a regularly scheduled passenger flight from San Luis Obispo, California, to Los Angeles, California, on January 2, 2006. The crew had set the autopilot of the Saab 340B+ (fig. 5) to maintain a climb rate that it was unable to maintain in the icing condition so the aircraft pitched up, slowed, and stalled while climbing through 11,500 feet. ${ }^{3}$ The crew recovered controlled flight at about 6,500 feet. Fig. 6 shows the crew maintained aft column for nearly 30 seconds and the aircraft quickly recovered when they finally moved the column forward. At stall, the aircraft experienced an un-commanded roll off, which was ineffectively opposed by opposite roll control. The figure also shows the pilot and co-pilot wheel in opposite directions near at the end of the upset. When icing is present on an $\mid$ airplane with reversible roll control, this can be caused by aileron hinge moment pulling the aileron up. 


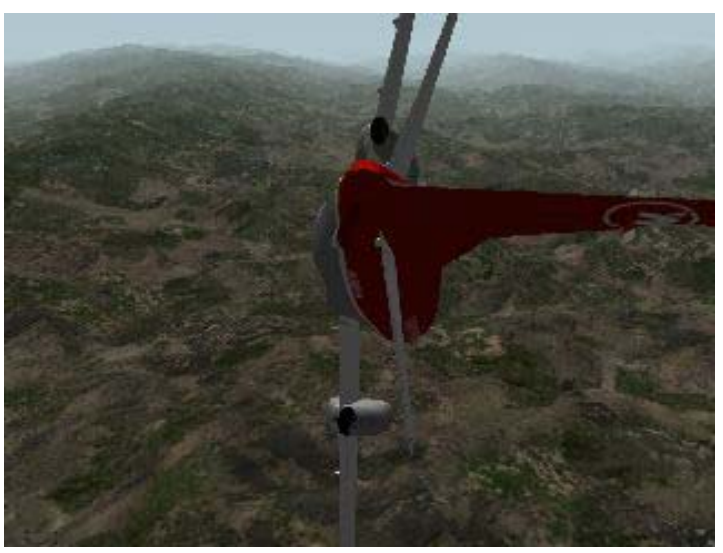

Figure 5. Saab 340.
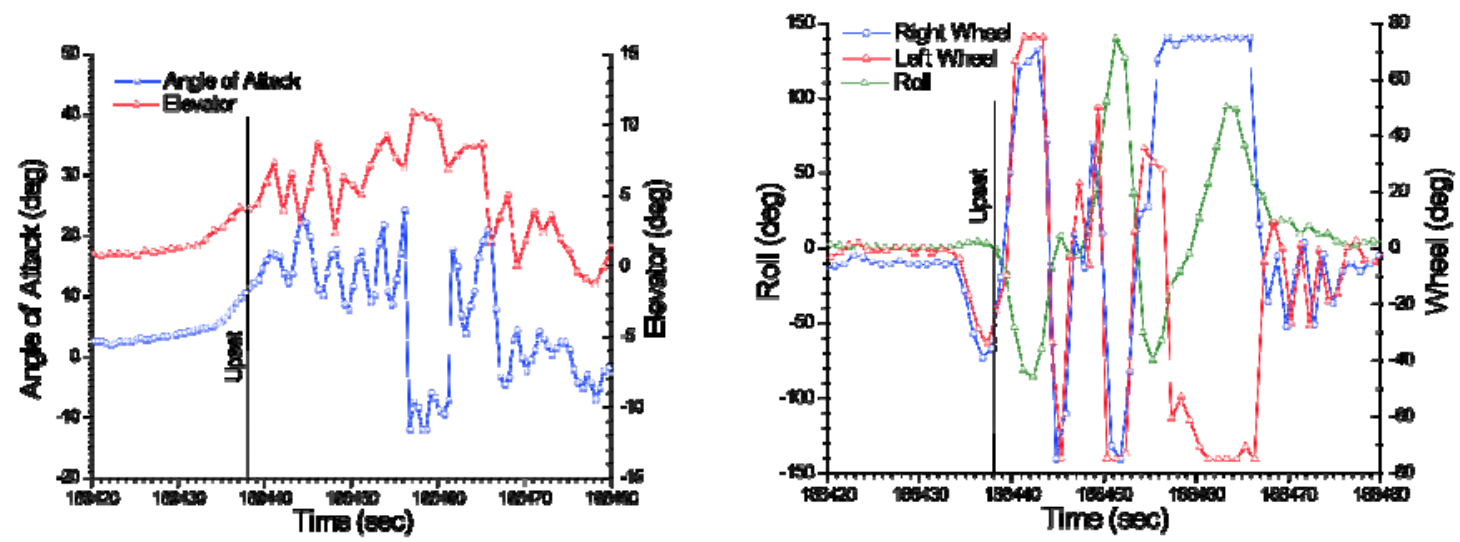

Figure 6. Time histories of American Eagle flight 3008 icing incident (San Luis Obispo).

The November 11, 1998, Saab 340A, VH-LPI, icing incident at Eilden Weir, Victoria, Australia, is the second flaps-up Saab 340 icing incident we will examine. The aircraft was on a regularly scheduled passenger flight from Albury, New South Wales, to Melbourne, Victoria. ${ }^{4}$ The crew noted ice accumulating on the wings and windscreen wipers as the aircraft was operating in instrument meteorological conditions. The crew felt that activating the wing de-icing system was not necessary for the level of icing encountered and proceeded to enter the holding pattern at Eildon Weir. The aircraft slowed and stalled without a stall warning, losing 2,300 feet of altitude before recovery. Time histories showing the stall and resulting uncommanded roll and ineffective wheel response are shown in fig. 7. 

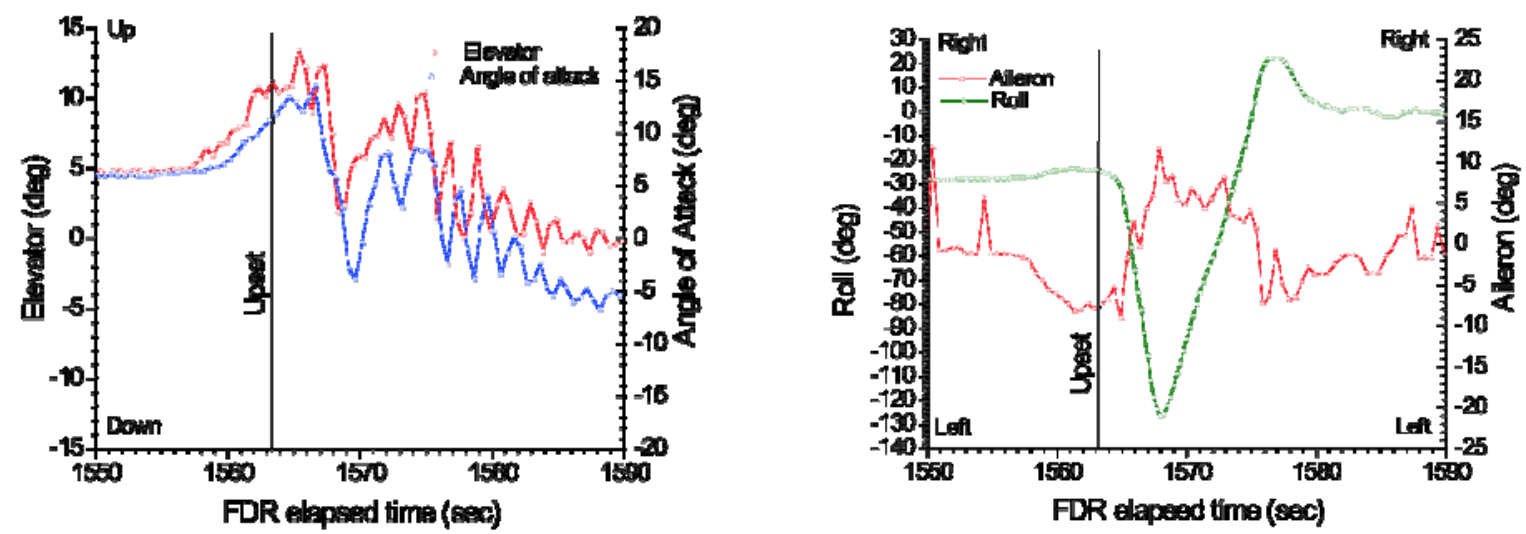

Figure 7. Time histories of VH-LPI icing incident (Eilden Weir, Victoria, Australia).

The third flaps up example is the June 18, 2004, incident at Albury, New South Wales. This shows the effectiveness of a proper response to a stall upset in icing. ${ }^{5}$ The Saab 340A, en route from Albury to Melbourne, Victoria, on a regularly scheduled passenger flight, leveled off at 12,000 feet and inadvertently began to slow. The pilot recognized the break with the uncommanded roll off as a stall and promptly (less than 3 seconds) moved the column forward. The pilot disconnected the autopilot as the stick shaker activated briefly and initiated a descent. The pilot's prompt forward column input, and resulting reduction in angle of attack (fig. 8), resulted in a negligible altitude loss in contrast to the other Saab 340 icing events. The un-commanded roll off and period of unresponsive roll control shown in the figure is much milder than those events in which the pilot did not reduce angle of attack promptly by moving the column forward.
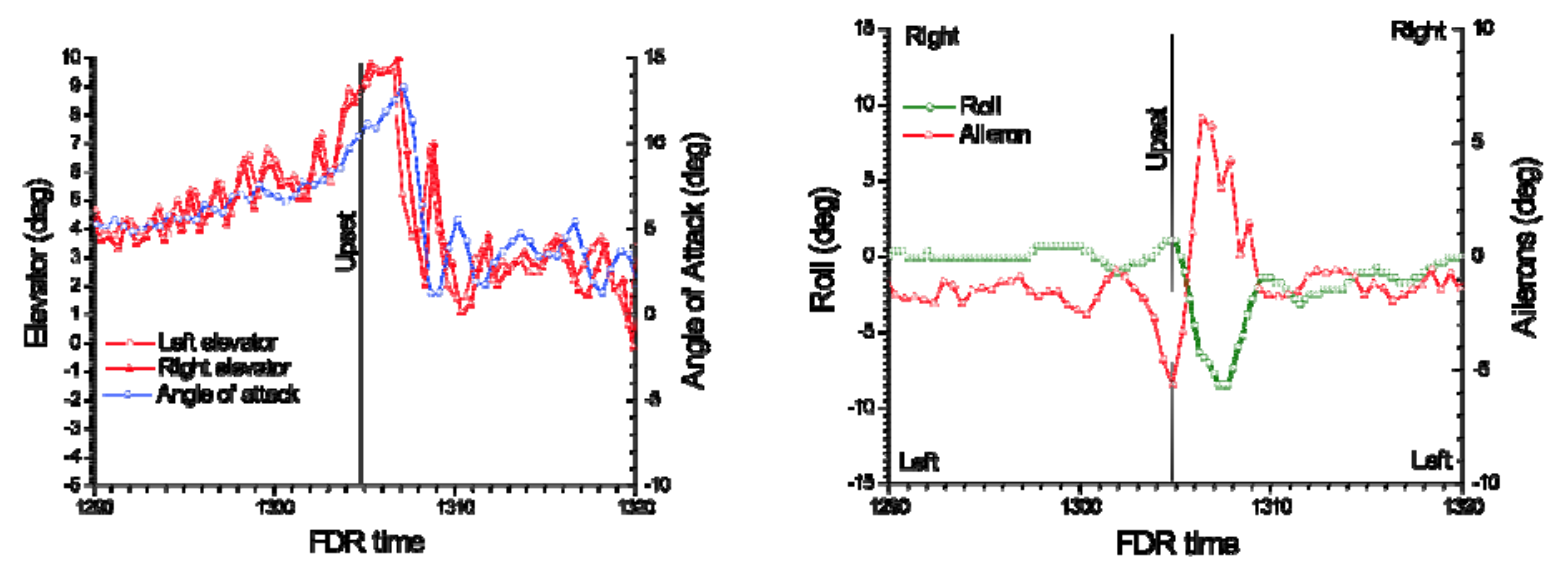

Figure 8. Time histories of VH-KEQ icing incident (Albury, New South Wales, Australia).

The NTSB used a kinematics parameter extraction ${ }^{6,7}$ to determine the aerodynamic degradation due to ice for the three flaps up Saab 340 icing upsets discussed above. The lift loss and resulting early stall (lower angle of attack 
than that for uncontaminated wing) for the three icing stall upsets are shown in fig. 9. Note that the icing degradation was more severe for the promptly recovered Albury event than for the other two icing upsets.
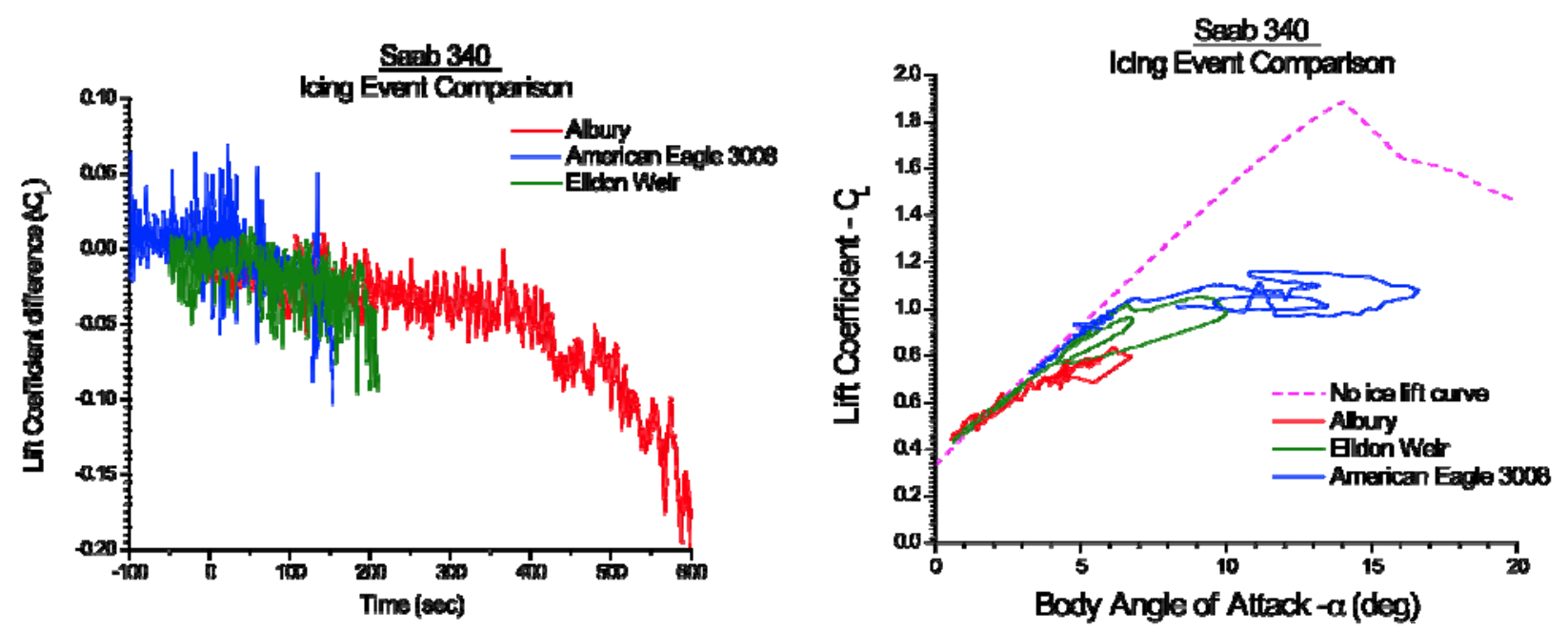

Figure 9. Summary of Saab 340 icing event lift degradation.

The effect of icing on aerodynamic forces and moments for the American Eagle flight 3008 icing upset is shown in fig. 10. The increase in drag represents the difference in drag for the aircraft at an angle of attack. Note that from an operations point of view, the aircraft is flying at a higher angle of attack due to the lift degradation. This leads to an additional increase in induced drag not shown in the figure. The time history of the difference in pitching moment coefficient for the incident shows what appears to be a slight nose down pitching moment change trend beginning at a time of about 22:38. The Saab 340 is an example of a design with co-rotating propellers and a vertical tail cant. Accordingly there are additional asymmetries in the lateral-directional parameters in icing. The figure also shows the changes in rolling moment and yawing moment coefficients along with the induced sideslip. 

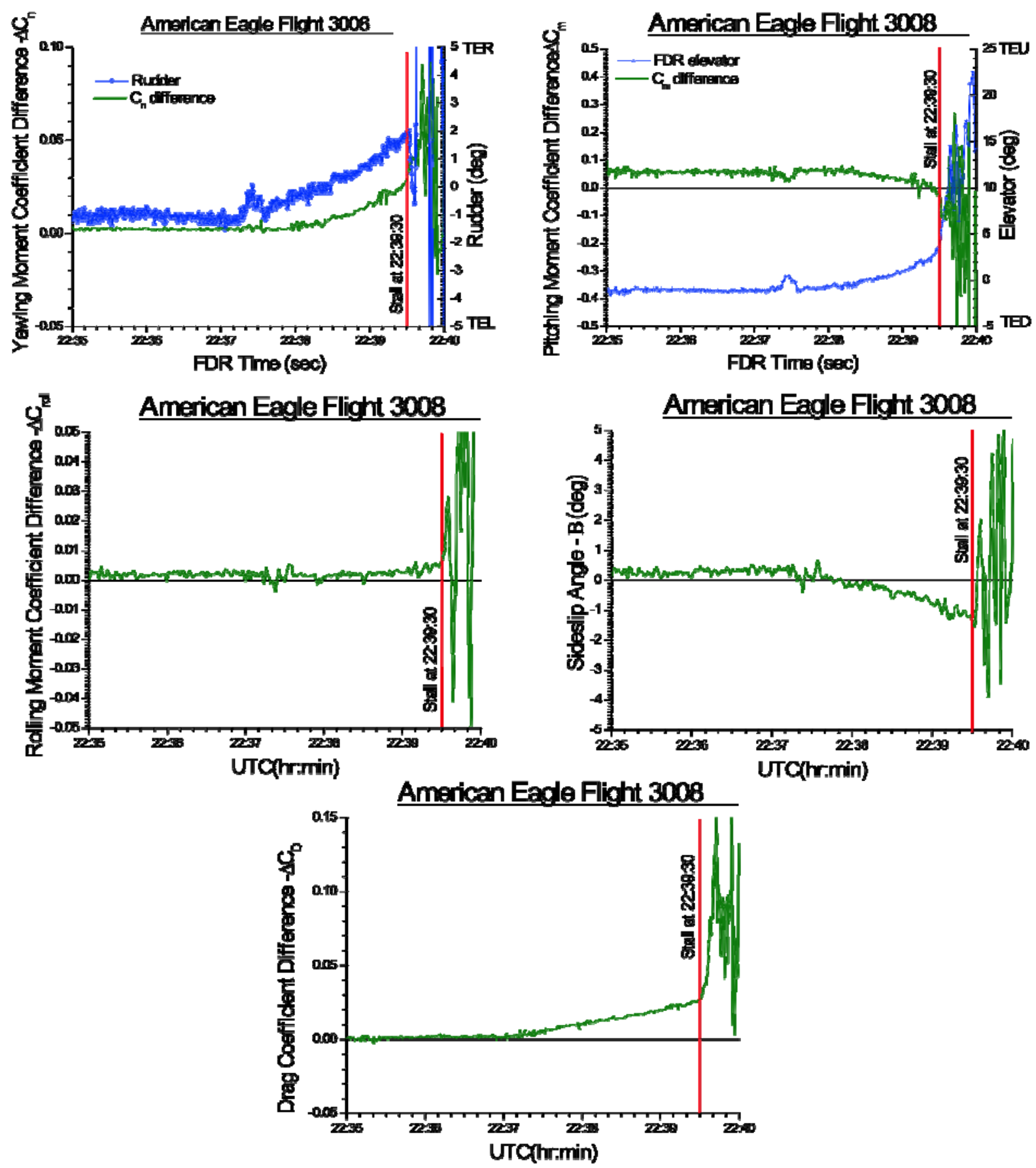

Figure 10. Aerodynamic degradation due to icing (American Eagle flight 3008 incident). 


\section{ATR-42 Upset}

The January 27, 2009, crash of Empire Airlines flight 8284 short of the runway at Lubbock, Texas, Preston Smith International Airport (fig. 11) provides an example of a loss of control accident due to stall in icing that further illustrates the aerodynamic characteristics of turboprop stall. ${ }^{8,9}$ The aircraft, an Avions de Transport Régional (ATR) Aerospatiale Alenia ATR 42-320 (ATR 42), was on a supplemental cargo flight from Fort Worth Alliance Airport (AFW) in Fort Worth, Texas. Time histories of flight data are shown in fig. 12(a). Extracted yawing moment and rolling moment are plotted with recorded controls are shown in fig. 12(b). Pitching moment and lift for this accident are discussed in a later section and shown in fig. 19 and 20. The aircraft showed an aerodynamic degradation due to icing in cruise that cleared as the aircraft descended. The crew failed to maintain the minimum safe airspeed in icing conditions and the stall warning stick shaker activated twice during the approach. The aircraft also experienced a flap asymmetry with the right flap retracted and the left flap between 8 and 10 deg, but this asymmetry cleared before the stall upset. While the flaps were asymmetric, however, the aircraft again encountered aerodynamic degradation due to icing in freezing drizzle. During the descent, the stick shaker activated three times, the last one occurring seconds prior to the stall upset and resulting crash. These stick shaker activations are indicated with recorded pressure altitude and airspeed for the landing approach shown in fig. 12(a).

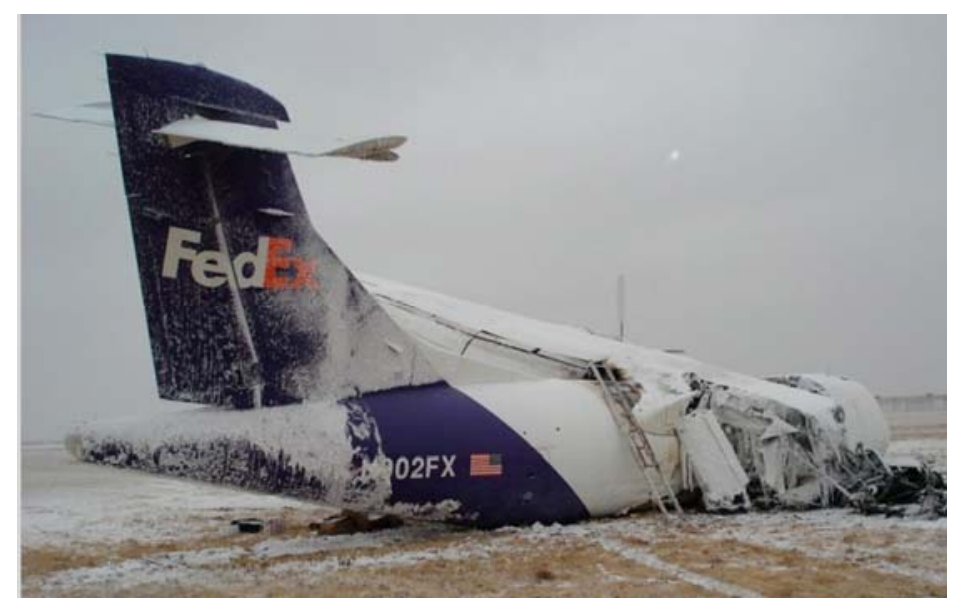

Figure 11. Empire Airlines flight 8284 icing accident (Lubbock, Texas). 

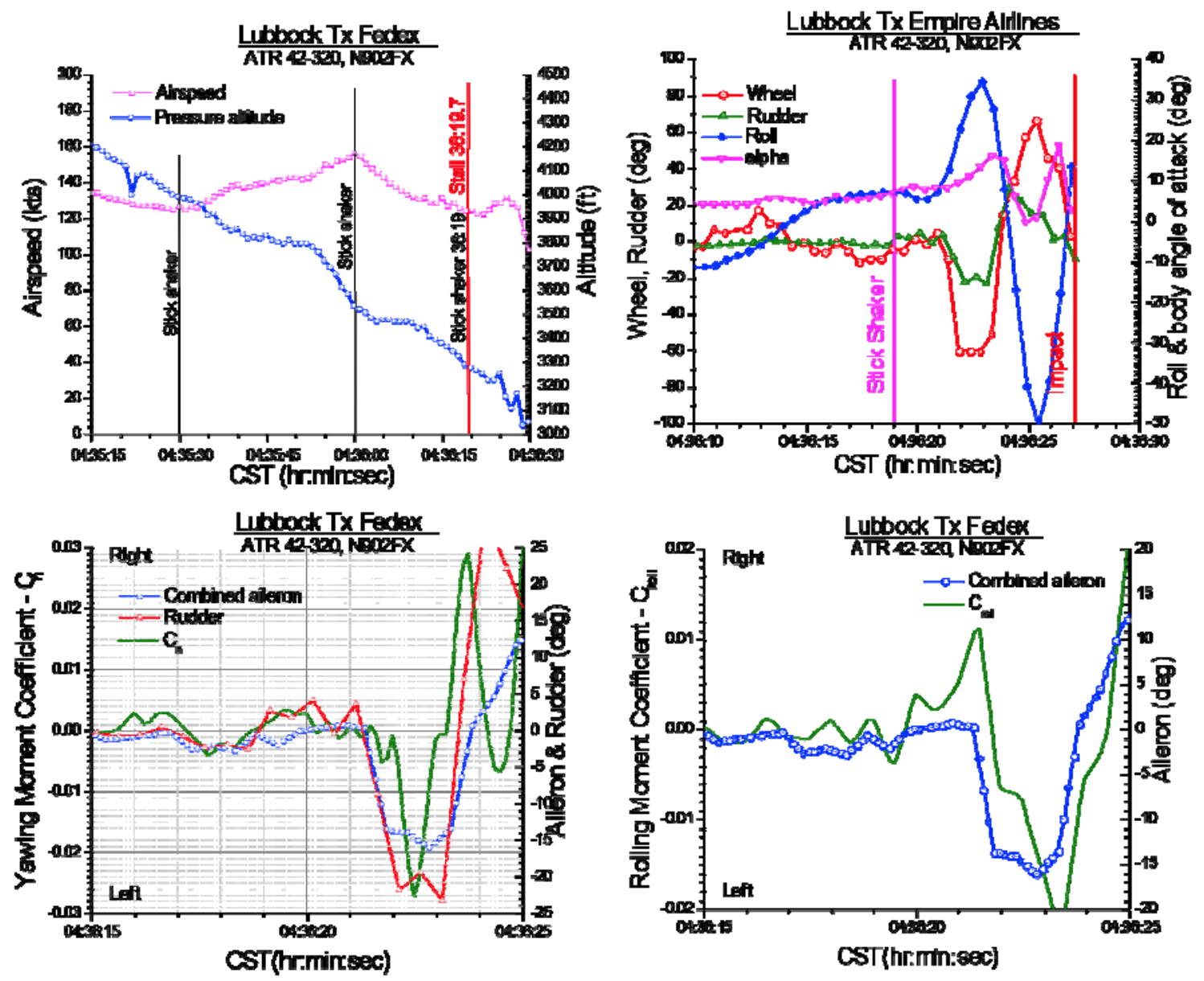

(a) Flight parameters and control inputs.

(b) Extracted aerodynamic yawing moment and rolling moment.

Figure 12. Time histories of Empire Airlines flight 8284 icing accident (Lubbock, Texas).

As a result of the Lubbock ATR-42 icing accident and earlier Saab 340 incidents, the NTSB made the following recommendations for enhanced simulator fidelity in icing and simulator training in icing.

\section{Recommendation A-11-46}

Define and codify minimum simulator model fidelity requirements for aerodynamic degradations resulting from airframe ice accumulation. These requirements should be consistent with performance degradations that the National Transportation Safety Board and other agencies have extracted during the investigations of icing accidents and incidents.

\section{Recommendation A-11-47}

Once the simulator model fidelity requirements requested in Safety Recommendation A-11-46 are implemented, require that flight crews of all aircraft certificated for flight in icing conditions be trained in flight training simulators that meet these fidelity requirements. Such simulation training 
should emphasize the following: (1) cues for recognizing changes in the aircraft's flight characteristics as airframe icing develops: (2) procedures for monitoring and maintaining appropriate airspeeds in icing conditions, including the use of icing airspeed reference indices: and (3) procedures for responding to decaying airspeed situations, stall protection system activation, and early stalls that can occur without stall protection system activation.

\section{Configuration Effects Modeling}

Turboprop transport aircraft typically incorporate straight wings, and those currently in airline service generally fall into two distinct configurations: those with high wing-mounted engines and a T-tail (fig. 2) and those with low wing-mounted engines and a conventional tail (fig. 5). As highlighted by the discussion in the previous section, these configurations can pose unique modeling challenges compared to larger swept-wing jets that must be considered and, in some cases, are more complex.

The aerodynamic forces and moments from stall warning through full stall are largely influenced by the flow separation pattern on the wing and the impingement of separated flow on the empennage. In some instances forebody separation can have important effects as well although it is not as dominant for typical transport shapes. Modeling requirements must include the effects of lift characteristics, but perhaps more importantly the effects on body-axis moments and the resulting impact on stability.

The following section will discuss important configuration effects that may be required to meet stall training requirements. These effects include;

- Wing stall progression from stall warning through full stall,

- Tail configuration,

- Induced and direct thrust,

- Contaminated lifting surfaces, and

- Dynamic lift/stick pusher coupling.

This discussion is presented as a general overview to bring attention to important modeling topics and to motivate future research. More detailed discussion is warranted for specific modeling implementations.

\section{A. Comparison of Straight-Wing versus Swept-Wing Stability and Control}

For a straight-wing configuration, flow separation typically starts near the wing root and progresses outboard such that roll control surfaces remain effective through the approach to stall. The stall pattern for a swept wing can be more complicated due to influences of spanwise flow, wing twist, and trailing edge separation. Figure 13 shows a conceptual comparison of lift curves for swept-wing and straight-wing configurations indicating that the straight wing may exhibit a more abrupt lift loss at stall than that for a swept wing. However, trailing edge flap position can significantly alter stall behavior resulting in abrupt stall behavior for swept-wing configurations as well. 


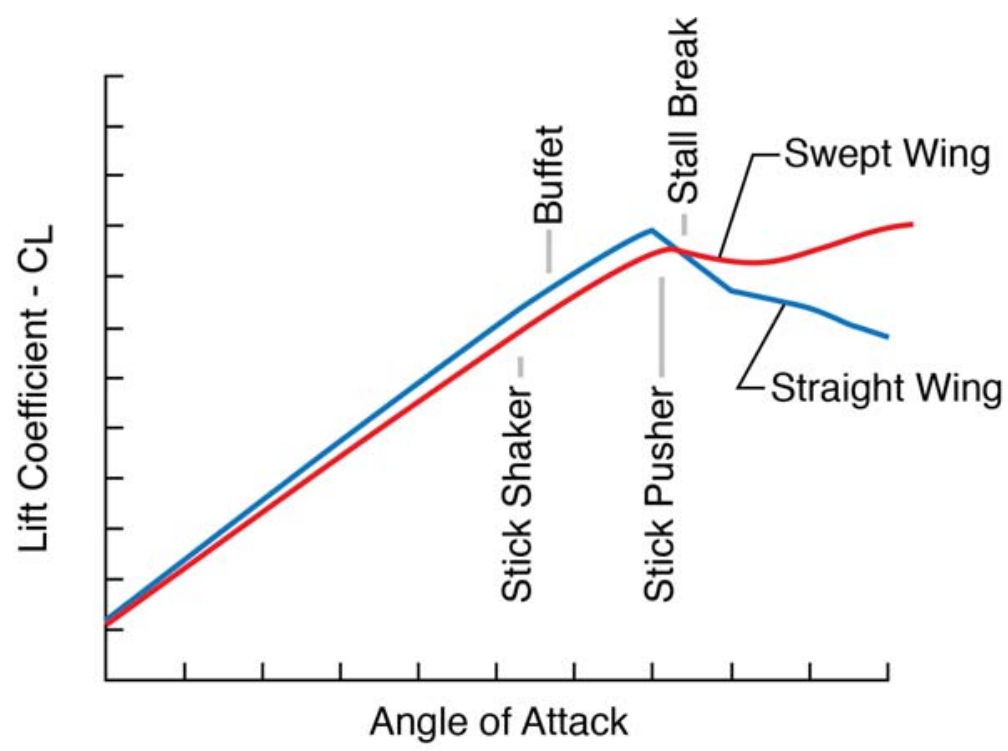

Figure 13. Typical lift characteristics for swept- and straight-wing aircraft (ref. 10).

Figure 14 shows a generalized effect of wing sweep on pitch stability at stall, indicating higher sweep reduces static pitch stability at stall which manifests as an uncommanded "pitch up." The cross-hatched area indicates the potential range of "pitch-up" severity. Based on this figure, typical turboprop transports with an aspect ratio of 10 or greater would be expected to exhibit mild pitch behavior at stall. For straight wing configurations, the center of lift does not shift significantly and the variation in pitching moment due to stall progression is generally small.

However, the additional effect of horizontal tail configuration can have large effects on pitch stability and will be discussed in the following section.

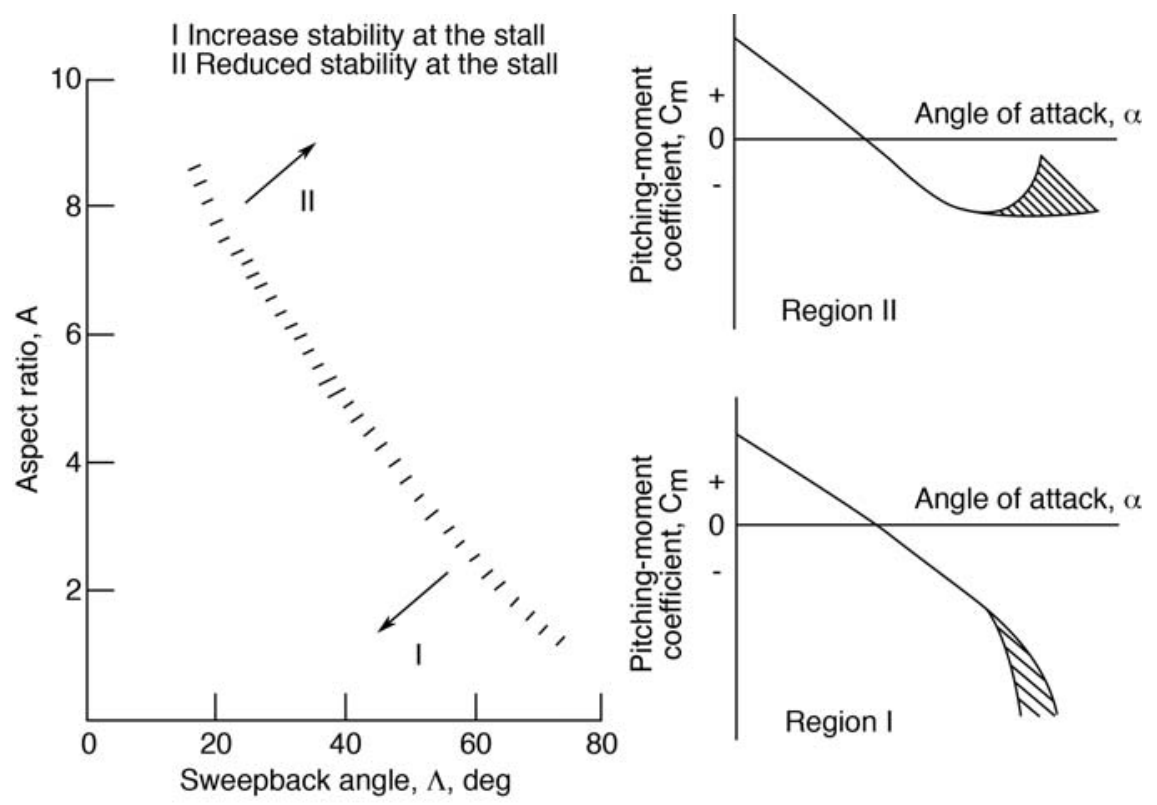

Figure 14. Effects of wing sweep on pitch stability (ref. 11). 
Examples of pitch stability for straight-wing and swept-wing T-tail configurations are shown in figure 15. These data show that pitch stability for both configurations remains positive and increases (see Region I, fig. 14) until beyond the stall angle of attack, where a sharp instability occurs. This instability creates what is sometimes referred to as the "pitch bucket," as illustrated in the figure, which is one indicator of the severity during stall progression; a wider bucket producing less severe changes in pitch stability. The more abrupt lift loss at stall for the swept-wing configuration is noted, probably due to the influence of flap deflection.

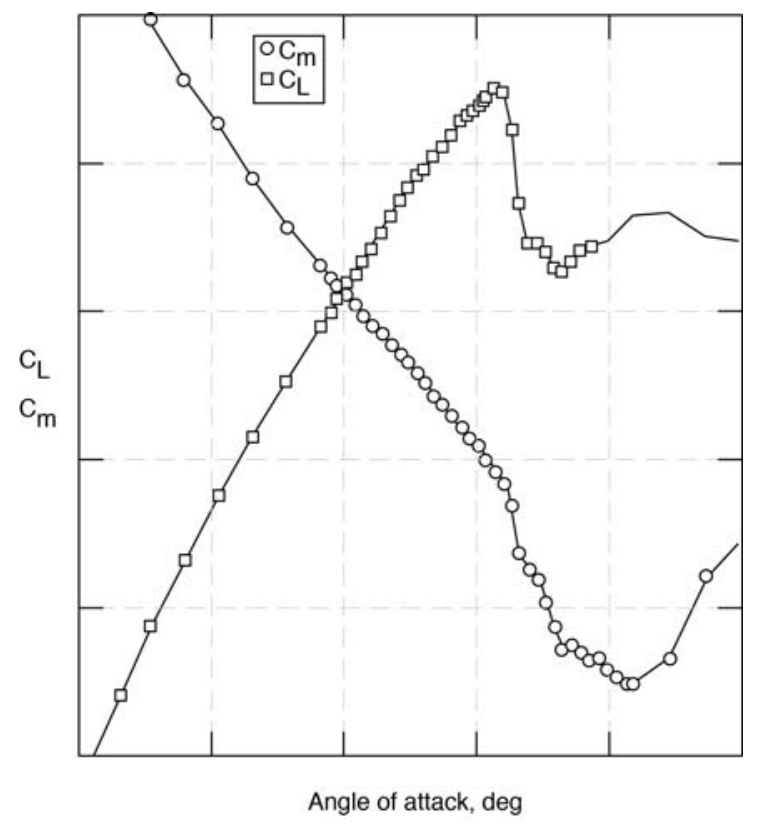

(a) Swept Wing (flaps down) (ref. 12)

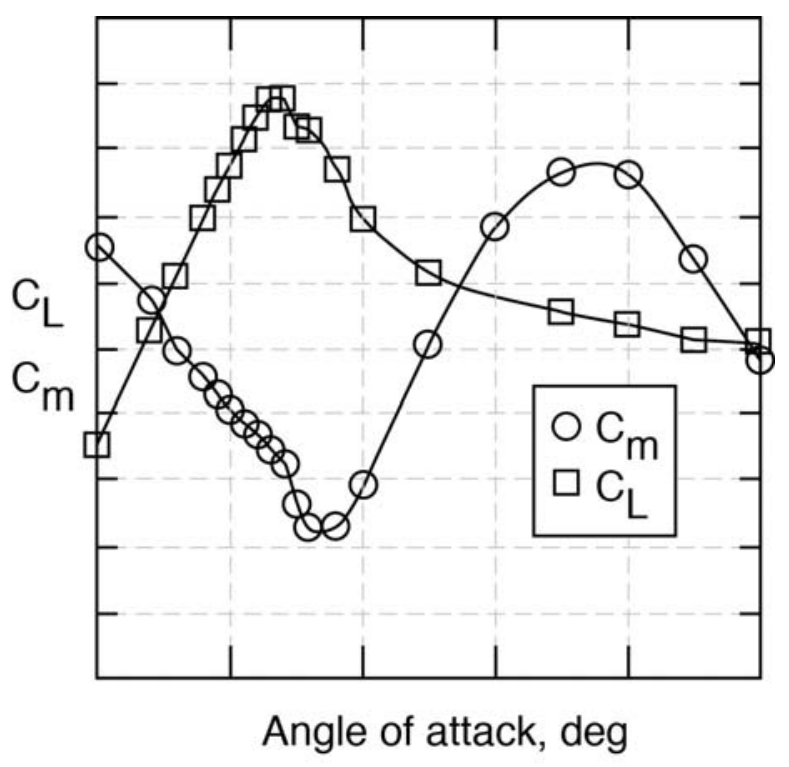

(b) Straight Wing (flaps up) (ref. 13)

Figure 15. Pitch stability for T-tail configurations with swept and straight wings.

\section{B. Tail Configuration}

The tail configuration can have significant influences on stall behavior and is perhaps the most important modeling effect to consider. Figure 16 illustrates the relative geometry of the wing wake and horizontal tail location and the resulting impact on pitch stability. For the conventional-tail configuration, pitch behavior is often characterized by a reduction in static stability (annotated as position 1) as the horizontal tail first enters the wing wake. Because the wake is fairly narrow at this point, due to the low angle of attack, this effect is generally limited and stability is re-established when the tail is below the wake at higher angles of attack. Positive stability is typically maintained at stall and beyond. In contrast, the horizontal tail for the T-tail configuration enters the wake at a higher angle of attack, where the wake is wider, which can result in an instability or severe "pitch up" and deep stall (annotated as position 2). From the figure, it can be observed that blanking of the vertical tail can be different between these two configurations, resulting in differences in directional stability as well. 

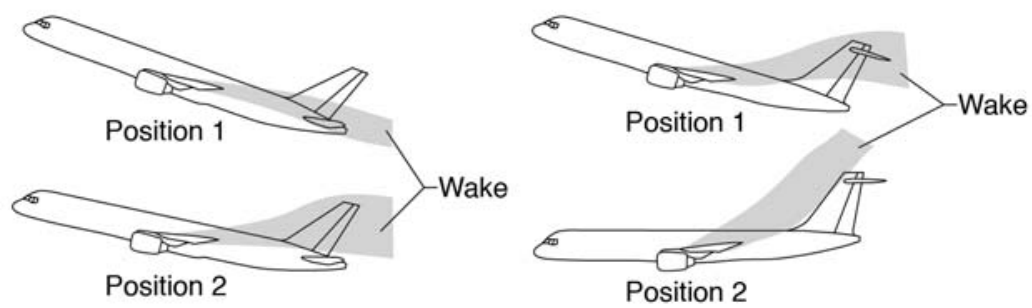

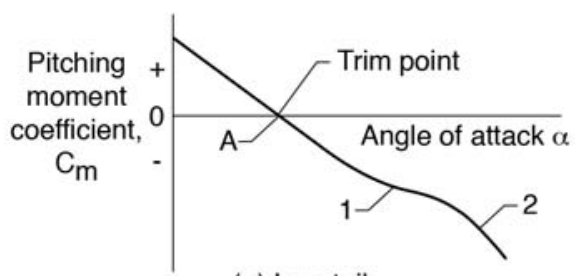

(a) Low tail

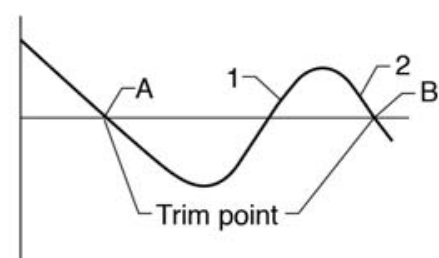

(b) High tail

Figure 16. Influence of tail configuration on stall behavior (ref. 11).

Figure 17 shows examples of aerodynamic lift and pitching moment for swept-wing jets with a conventional tail and T-tail configuration. Both configurations indicate similar variations in pitch stability near stall, however an abrupt lift loss at stall and a strong post-stall instability is apparent for the T-tail configuration.

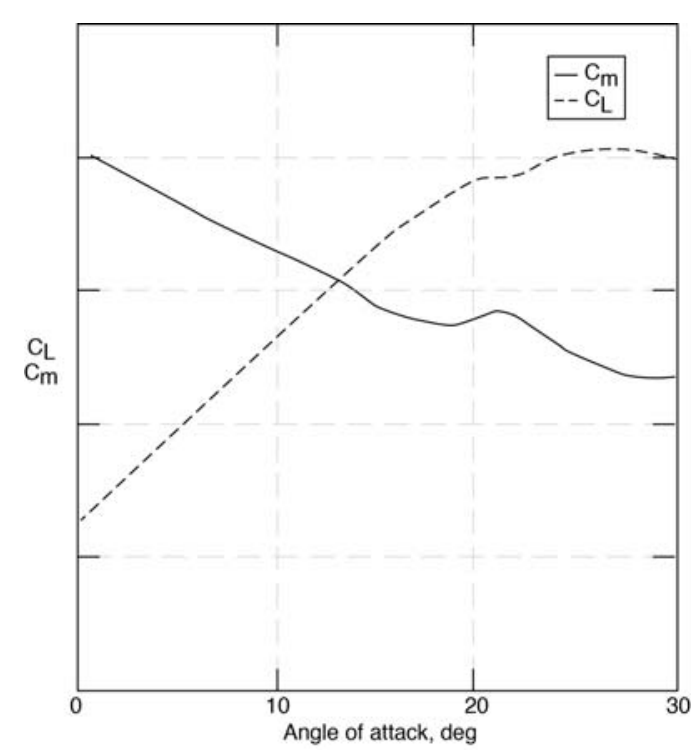

(a) Conventional Tail (ref. 14)

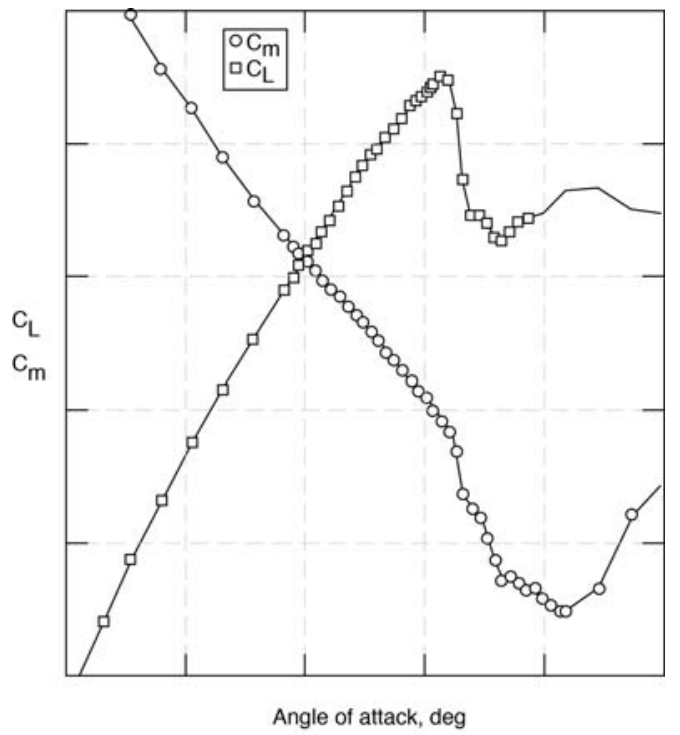

(b) T-Tail (ref. 12)

Figure 17. Lift and pitching moment for swept-wing jets, flaps down.

\section{Thrust effects}

Direct thrust effects refer to the moment created due to the thrust line being offset from the center of gravity (CG). For aircraft with high wing-mounted engines, a thrust increase creates a direct nose-down moment, which may be helpful for stall recovery in some instances. In contrast, aircraft with low wing-mounted engines exhibit a nose-up response due to thrust application, an effect that must be compensated for during stall recovery. Although not an aerodynamic effect, the thrust line effect is often extremely important for stall recovery modeling. 
Induced thrust effects include the change in aerodynamic forces and moments solely due to the change in flow field from thrust. This includes the propwash behind the propellers that may impinge on the wing or empennage or due to entrainment of flow ahead of the propellers. It is well known that lift enhancement from thrust can be achieved, such as with blown flap configurations, however stability can also be significantly altered. For example, figure 18 shows the effects of induced thrust on pitching moment for a high wing turboprop with two flap settings. These data show a significant pitch up due to increased thrust, and this effect is most pronounced near stall. It is also observed that the pitch up is nearly twice that for flaps down compared to flaps up. The pitch-up is likely due to changes in the wing moment as well as changes in downwash angle or flow velocities at the horizontal tail. In contrast, swept-wing jets may exhibit much smaller induced thrust effects, primarily limited to downwash influences on the horizontal tail.

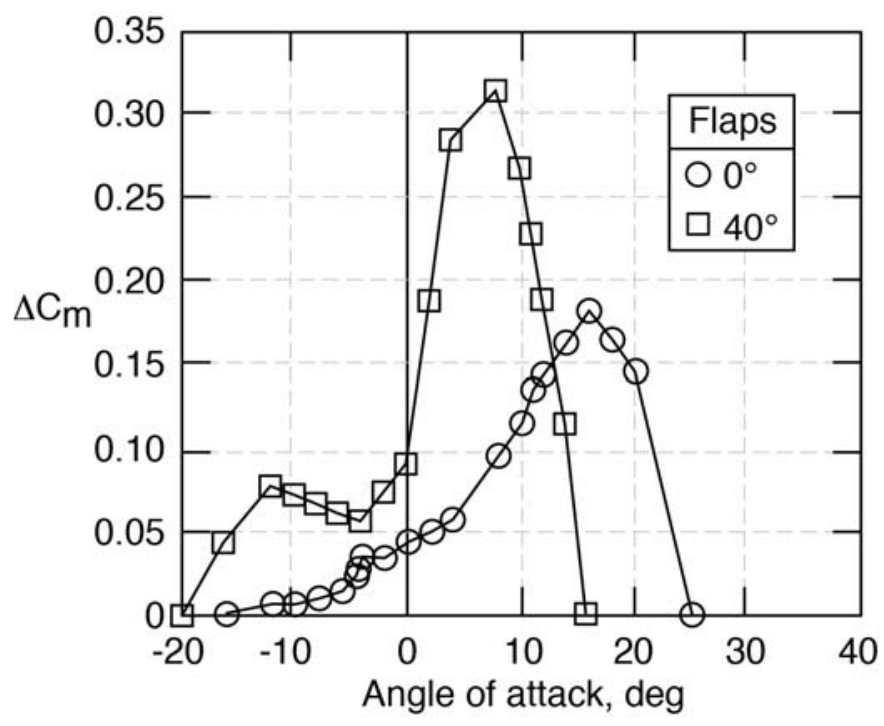

Figure 18. Effect of thrust on aerodynamic pitching moment for a high wing turboprop, conventional-tail configuration (ref. 15).

Figures 19 and 20 show examples of power effects extracted from the icing accident previously discussed in figure 12. Post-stall lift behavior can be explored further by co-plotting lift coefficient with power settings and angle of attack. The peak lift occurs at $t=4: 36: 20.5$, indicating early stall due to icing. The increase in lift after the initial stall lift loss appears coincident with an increase in power, indicating probable influence of propwash on stall angle of attack. Figure 20 shows the lift curve extracted for this aircraft for a prior flight without icing co-plotted with the accident flight. The early stall in icing is clearly seen. Lastly, the extracted pitching moment data in fig. 20 also suggests strong induced thrust effects on aerodynamic stability. 


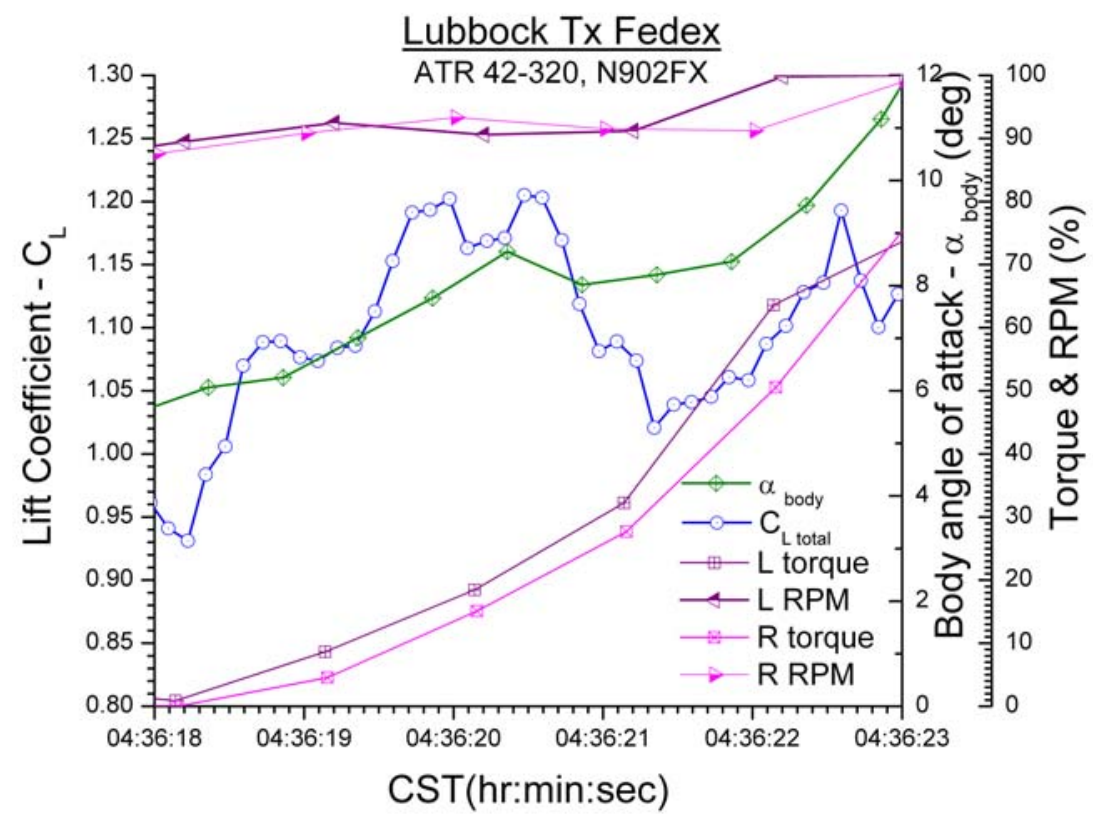

Figure 19. Effect of power on lift coefficient for a high wing, T-tail configuration (ref. 8).
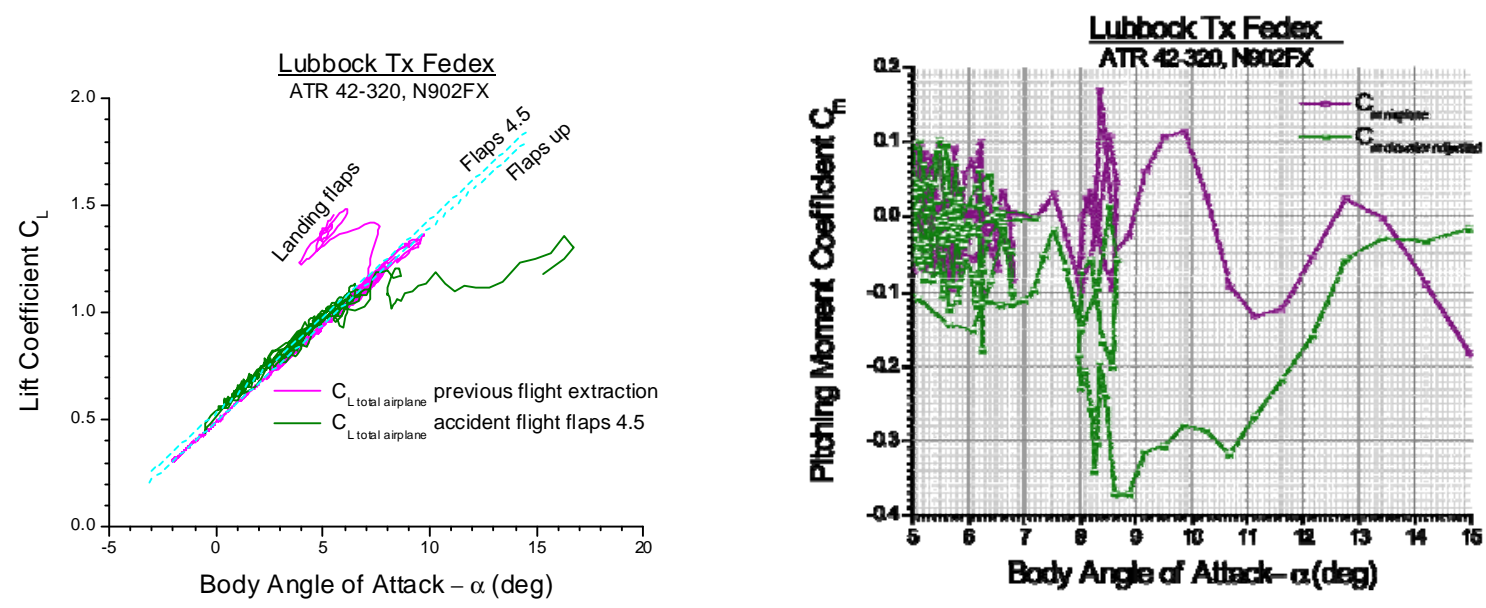

Figure 20. Extracted lift and pitching moment curves (ref. 8).

Reference 15 discusses the complex effects of induced thrust on stability in the presence of contaminated surfaces. In the presence of icing, pitch damping was reduced with thrust on but was not changed with idle thrust. In contrast, static directional stability was altered by icing only with idle thrust.

\section{Contaminated Lifting Surface Modeling}

The NTSB recognizes icing as one of the most important threats to aviation safety today. The previously discussed examples of icing incidents and accidents clearly illustrates the degradation in aircraft stability and performance from which recovery may be difficult and leading to an accident. Figure 20 provides a conceptual 
illustration of the effect of icing on lift, and that is the reduction of lift at pre-shaker angles of attack and the resulting stall at higher than normal airspeeds (early stall). Not only is performance severely degraded by reduction in lift and increase in drag, the accompanying degradation in aerodynamic stability can result in unmanageable flying qualities and performance.

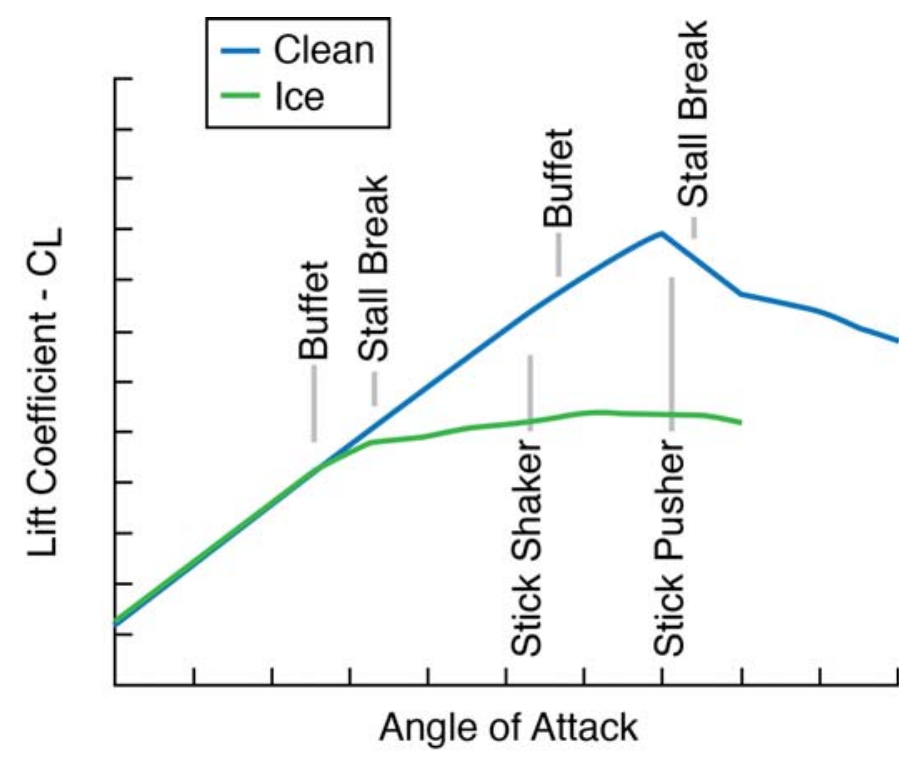

Figure 20. Generalized effect of wing icing on lift (ref. 10).

To date, modeling of icing effects is often limited to the performance degradation due to increased weight from ice buildup; however, other effects previously mentioned, such as stability degradation, are often not modeled. Modeling icing simply as an increase in weight misses the critically important low angle of attack (early) stall as well as other critical characteristics and may thus result in negative transfer of training. Modeling of icing effects on aerodynamic behavior remains an important area for development.

The predominance of icing research over the past decade has been conducted by the NASA Glenn Research Center in partnership with industry researchers and manufacturers, which has been aimed at the problem of stability and control degradation due to ice accumulation. References 15-19 provide important experimental ground and flight test results for icing simulation and training. These references include experimental data and discussion on two straight-wing configurations: a high wing, conventional-tail turboprop (NASA Glenn Twin Otter) and a low wing Ttail business jet (CJ-2).

Reference 15 provides one of the earliest summaries of the effects of airframe ice on aerodynamic stability and control behavior. Degradations in control effectiveness up to $10 \%$ and reductions in static stability from 10-20\% were shown. Reference 17 provides further data on the degradation in dynamic stability due to icing, most notably dynamic roll instabilities created by icing at angles of attack near stall. Figure 21 shows results from reference 17 for various levels of icing and the influence on pitch stability throughout the angle of attack range. 

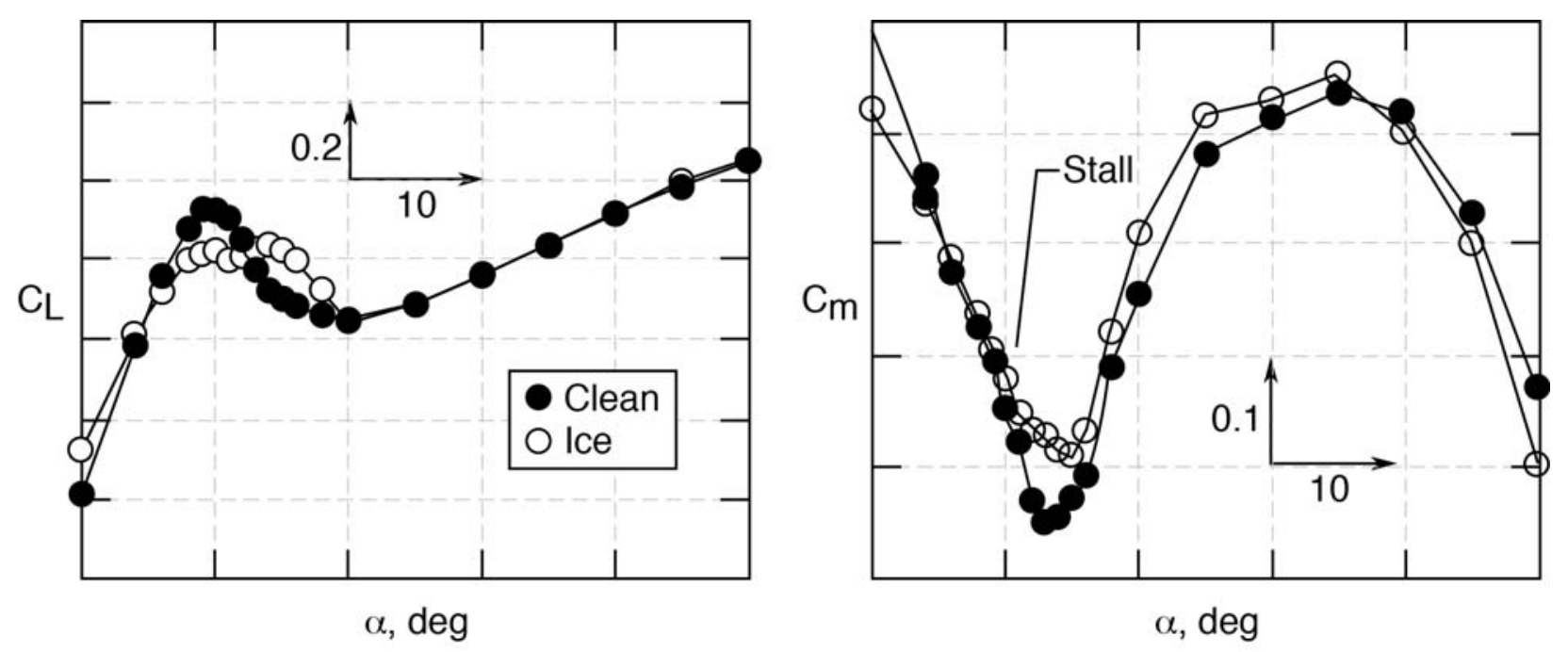

Figure 21. Effects of wing ice on lift and pitching moment for a high wing, conventional-tail configuration (ref. 17).

\section{E. Dynamic Stall/Stick Pusher Coupling}

The Colgan Air accident previously discussed illustrates a phenomena unique to aircraft equipped with stick pushers that can have important implications on unsteady aerodynamic characteristics. Often referred to as "dynamic stall," large amplitude pitching motions are known to create lags or hysteresis in aerodynamic lift and pitching moment due to the time required to stabilize separated flow. Previous research has documented this effect and it is sometimes included in aerodynamic models for large transports. Although the influence of this effect on flight trajectories or stall recovery is largely undocumented, the topic should be addressed as stall models are incorporated in training simulators.

Based on the time histories in fig. 4, large-amplitude pitch excursions involving variations in angle of attack of over 30 deg occurred with high pitch rates. One explanation was that the pilot was startled by the uncommanded column forces induced by the stick pusher and attempted to oppose the forces by applying full aft column inputs, thereby inducing stall. Although this was an improper response, and one that would be addressed by training, this serves to illustrate the need to consider unusual or unanticipated circumstances in simulator modeling. Previous research has shown the presence of dynamic stall by the hysteresis in lift in the presence of large-amplitude, oscillatory pitch rates. While the impact of this effect has not been documented, the potential effect on stall training, and more importantly stall recovery, remains a topic for further research.

\section{Summary and Recommendations}

This paper has presented an overview of the increasing motivation for improved stall modeling of turboprop transport airplanes. Recent accidents have highlighted the vulnerability of these configurations to upsets due to stall, with both contaminated and uncontaminated lifting surfaces. Furthermore, the unique operational environment provides increased exposure to icing potential that has directly led to accidents. Because turboprops typically are straight-wing configurations, the stability and control characteristics at high angles of attack pose a unique modeling challenge compared with large swept-wing jets. Modeling of certain characteristics unique to turboprops, such as induced thrust effects, remain largely unexplored for stall/post-stall flight conditions. Based on the literature search conducted for this paper, the availability of open-source data for stall aerodynamics modeling on straight-wing turboprops, especially induced aerodynamic effects, is limited.

The recent mandate for airline stall training has added an urgency to the need for improved stall modeling for turboprop aircraft. Industry efforts are in progress to develop stall training needs that will include the associated 
modeling requirements for effective skill development. The need for aerodynamic models for effective training is an important challenge that requires research and development efforts for the foreseeable future.

Based on recent accidents and published data, additional research is needed to fully address the modeling needs for turboprop aircraft. Wind-tunnel experimental testing is warranted to study stall and post-stall conditions with various horizontal tail configurations. Also, very little data is available for modeling induced thrust effects on stability and control behavior, with and without icing. Modeling these effects is critical for understanding the most critical conditions that have contributed to accidents. Additionally, asymmetric icing effects remain an area for additional research. Lastly, dynamic stall remains an area largely unexplored for turboprop configurations.

\section{References}

${ }^{1}$ Airclaims, Ascend database, www.ascendworldwide.com

2 National Transportation Safety Board, 2004, Loss of Control on Approach Colgan Air Inc Operating as Continental Connection Flight 3407 Bombardier DHC-8-400, N200WQ Clarence Center, New York, February 12, 2009, Aircraft Accident Report NTSB/AAR-10/01, Washington, DC.

${ }^{3}$ National Transportation Safety Board, "Brief of Accident LAX99LA291”, Washington, D.C., 2001.

${ }^{4}$ Australian Transportation Safety Bureau, 2001 “Saab - SF340A, VH-LPI Eildon Weir, Victoria on 11 November 1998 ”, Report 199805068.

${ }^{5}$ Australian Transportation Safety Bureau, 2005 “Aviation Safety Investigation Report - Final, Saab Aircraft Co SF-340A, VH-KEQ."

${ }^{6}$ Crider, D.A., “Accident Kinematics Parameter Extraction, A Simulation Tool," 2003 AIAA Modeling and Simulation Technologies Conference and Exhibit, AIAA-2003-5377, Austin, TX, 2003.

${ }^{7}$ Crider, D.A., "Enhancements to the Kinematics Parameter Extraction Simulation Tool," 2006 AIAA Modeling and Simulation Technologies Conference and Exhibit, AIAA-2006-6819, Keystone CO 2006.

${ }^{8}$ National Transportation Safety Board, 2011, Crash During Approach to Landing Empire Airlines Flight 8284 Avions de Transport Regional Aerospatiale Alenia ATR 42-320, N902FX Lubbock Texas January 27, 2009, Accident Report NTSB/AAR11/02, adopted April 26, 2011.

${ }^{9}$ National Transportation Safety Board, Empire Airlines Flight 8284 Kinematics Extraction Study, Oct. 5, 2011.

${ }^{10}$ Weener, Earl "Lessons from Icing Accidents and Incidents," presented to Experimental Aircraft Association, Feb 1, 2011.

${ }^{11}$ Loftin, Laurence K., Jr., “Quest for Performance: The Evolution of Modern Aircraft”, NASA SP-468, 1985.

${ }^{12}$ Kafyeke, Fassi, Pepin, Francois, and Kho, Cedric; "Development of High-Lift Systems for the Bombardier CRJ-700, ICAS 2002 Congress, paper 3101.

${ }^{13}$ Barnhart, Billy; “CJ2 Icing Effects Simulator”, AFRL-RB-WP-TR-2007-3116, August 2007.

${ }^{14}$ Cunningham, Kevin, Foster, John V., Shah, Gautam H., et al; , "Simulation Study of Flap Effects on a Commercial Transport Airplane in Upset Conditions”, AIAA 2005-5908, Aug., 2005.

${ }^{15}$ Ratvasky, T.P., Ranaudo, R.J., "Icing Effects on Aircraft Stability and Control Determined from Flight Data - Preliminary Results”, NASA TM-105977, AIAA-93-0398, January 1993.

${ }^{16}$ Barnhart, Billy P., Dickes, Edward G., Gingras, David R., and Ravatsky, Thomas P., "Simulation Model Development for Icing Effects Flight Training,”, SAE 2002-01-1527, April, 2002.

${ }^{17}$ Lee, Sam, Barnhart, Billy P., et al, “Dynamic Wind-Tunnel Testing of a Sub-Scale Iced Business Jet,” NASA TM-214268, 2006.

${ }^{18}$ Barnhart, Billy P., and Ratvasky, Thomas P., "Effective Training for Flight in Icing Conditions,” NASA TM-2007214693, March 2007.

${ }^{19}$ Ratvasky, Thomas P., Blankenship, Kurt, Rieke, William, and Brinker, David J., “Iced Aircraft Flight Data for Flight Simulator Validation”, NASA/ TM-2003-212114, SAE-2002-01-1528, April 2003. 